\title{
POSITIONAL CONTROL OF LASER PHOTOCOAGULATOR LESIONS NEAR THE FOVEA* $\dagger$
}

BY

\author{
D. C. WEST
}

\section{J. J. Thomson Physical Laboratory, University of Reading}

THE design and use of laser photocoagulators for the treatment of pathological conditions in the eye has been described by Ingram, Manson, and Smart (1965) and Ingram (1966). When lesions need to be made close to the fovea, extremely precise positional control of the lesion is necessary. Involuntary eye movements (Boyce, 1967; Ditchburn and FoleyFisher, 1967) and human reaction times become important sources of error. With conventional photocoagulators destruction of part of the fovea could obviously ensue. This paper describes an optical system which nullifies such sources of error; once the site for the lesion is chosen, the actual lesion must occur there and nowhere else, despite eye movements and length or number of the exposures.

\section{Method}

The apparatus (Figure) consists of three basic parts:

(a) Illuminating System.-The components $\mathrm{S}$ (source), $\mathrm{L}_{1}, \mathrm{~A}, \mathrm{D}, \mathrm{L}_{2}, \mathrm{~F}$ (filter), T (movable graticule), $\mathrm{L}_{3}$, constitute a system for illuminating the fundus and for projecting an image of a graticule $(\mathrm{T})$ on to the desired position for the lesion.

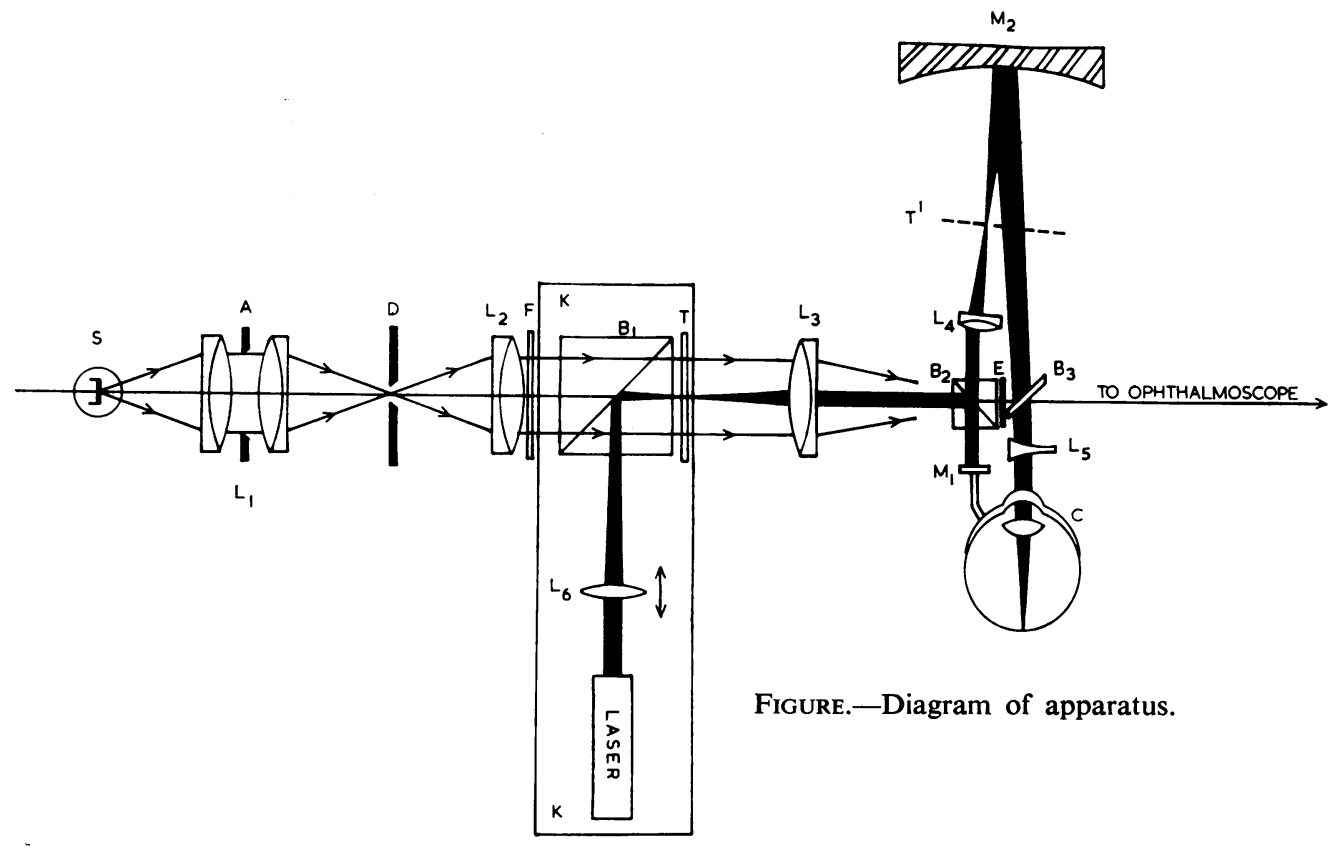

* Received for publication November 27, 1967.

† Address for reprints: Road Research Laboratory, Ministry of Transport, Crowthorne, Berks. 
(b) Laser System.-The laser is carried on a kinematic carriage (K) constrained to move in a plane perpendicular to the optical axis of the illuminating system. The laser beam axis always coincides with the centre of graticule T. Motion of $\mathrm{K}$ permits variation in the site of the lesion. Variation of the power of $L_{6}$ allows the laser beam diameter to be varied. The laser beam is parallel as it enters $B_{2}$ and is reflected from $M_{1}$.

(c) Stabilizing System.-A retinal image stabilizing system, consisting of components $M_{1}$ (a flat mirror, carried on a contact lens, $C$, worn by the subject), $B_{2}$ (beamsplitter), $L_{4}, M_{2}, B_{3}$ (permitting ophthalmoscopy), $L_{5}$, and $C$. The basic stabilizing system has been described by Ditchburn (1963), and its use by West (1967). The contact lens detail has been described by West and Boyce (1968).

Since the laser beam traverses the retinal image stabilizing system before entering the eye, its image is stationary on the retina despite eye movements or small translations of the eye or head as a whole. Compensation for such movements can exceed 98 per cent. Also, the image of $\mathrm{T}$ is stabilized, and the position for the lesion may be selected as accurately as the optics of the eye permit.

There is not space to elaborate on procedure, but mydriatics would be necessary to avoid damage to the pupil (Ingram, 1966) and mild corneal anaesthesia would be required to enable the subject to tolerate a tight contact lens. Protection to the observer's eye would be afforded by 2-mm. thick B.G.18 filters, and suitable safety interlocks between filter and exposure of the laser.

There are other possible uses for this method, e.g. in micro-stimulation of the retina in electro-physiological studies of animal visual processes.

\section{Summary}

An optical system is described which, when used with a laser photocoagulator, would allow lesions safely to be made very close to the fovea. The system compensates for at least 98 per cent. of the motion of the retinal image due to eye movements, and allows very precise control over the position of the lesion, in any region from the fovea out to an eccentricity of at least $10^{\circ}$. There are uses for the method in many electrophysiological experiments on animal vision.

\section{REFERENCES}

BOyce, P. R. (1967). Proc. roy. Soc. B, 167, 293.

Ditchburn, R. W. (1963). Optica Acta, 10, 325. and Foley-Fisher, J. A. (1967). Ibid., 14, 113.

Ingram, H. V. (1966). Proc. roy. Soc. Med., 59, 215.

- Manson, N., and Smart, D. (1965). Brit. med. J., 1, 823.

WeST, D. C. (1967). Vision Res., 7, 949.

and BOYCE, P. R. (1968). Ibid., 8, 171. 